\title{
CONSIDERACIONES SOBRE ALGUNOS ELEMENTOS ENUNCIATIVOS EN LA LENGUA ESPAÑOLA
}

Concepción Otaola Olano

U.N.E.D.

\section{INTRODUCCIÓN}

El fin que persigue este trabajo es mostrar, a la luz de las teorías de la enunciación, algunos elementos existentes en la lengua española que son piezas clave en el proceso enunciativo, pues hacen posible la conversión de la lengua en discurso.

Para adentrarnos en el estudio de la enunciación consideramos inevitable una referencia a F. de Saussure y su concepto de lengua. Esta referencia resulta imprescindible pues existe un paralelismo entre la modificación 0 reformulación del concepto de lengua y, consiguientemente el de habla, propugnados por Saussure y el creciente desarrollo de las teorías de la enunciación dentro de la lingüística contemporánea.

Con Saussure nace la lingüistica moderna pues impulsa la investigación científica del lenguaje. Se centra en el estudio inmanente de la lengua como sistema dejando de lado el habla y, por tanto, la consideración del sujeto enunciador.

Ligüistas posteriores pudieron comprobar que esta rigidez y limitación en la concepción del objeto de la lingüística planteaba problemas e incluso constituia un obstáculo, especialmente, cuando se quería abordar el dominio de la significación, para el cual parece indispensable intentar alcanzar la lengua en su funcionamiento. Ya los sucesores de F. de Saussure, principalmente $\mathrm{Ch}$. Bally, plantean una lingüistica del habla tan importante como la lingüística de la lengua desarrollada por el maestro ginebrino. Se considera imposible referirse a la lengua entendida como un sistema totalmente distinto de su utilizador y de sus condiciones de utilización. Por tanto, para muchos lingüistas contemporáneos es evidente que las cuestiones del sujeto ya no se pueden mantener fuera del campo de la lingüística.

Con la incorporación a la lingüística del estudio del sujeto se abordan las investigaciones sobre la enunciación, hoy en pleno auge. El término enunciación se ha tomado en distintos sentidos dando origen a diversos enfoques en el estudio, como luego veremos. 
Para comprender lo que es la enunciación debemos partir de la diferenciación entre enunciación (producción) y enunciado (producto), es decir, entre el acto mismo de producir un enunciado y el texto del enunciado. Con el estudio de la enunciación, la lingüistica pretende indentificar y descubrir las huellas del acto (enunciación) en el producto (enunciado). En líneas generales podemos decir que la enunciación es el acto individual de utilización de la lengua y está constituida por el conjunto de factores y de actos que supone la producción de un enunciado.

El estudio de la enunciación se puede abordar a partir del discurso y a partir de la lengua. Dentro del primer enfoque se encuentran las teorías de la literatura (estilística, semiología, etc.), las teorías del discurso, las teorías de la argumentación, etc. En la perspectiva de la lengua se estudian los fenómenos enunciativos en lengua como la déxia, la modalidad, etc.

En la lingüistica contemporánea dos grandes corrientes se disputan el campo enunciativo. La primera, a la que podriamos denominar «enunciación en el sentido estricto del término" parte de la perspectiva de la lengua y estudia ciertos subsistemas de unidades de la lengua como los deícticos, las modalidades, etc., aunque también extiende su campo de acción al enunciado en su totalidad. Esta corriente es de inspiración neo-estructuralista y europea, concretamente, francesa. Sus principales representantes son Bally, Benveniste, Guillaume y Culioli. La segunda corriente, denominada "pragmática» es de inspiración lógica y anglosajona. Trabaja sobre el «lenguaje en actom. Se cultiva profusamente en Estados Unidos, en Alemania, en Inglaterra y también en Francia (Ducrot).

Para el estudio que nos proponemos realizar seguimos la línea de la primera corriente. Ésta intenta integrar el sujeto en el sistema mismo de la lengua en oposición a las corrientes lingüísticas que, debido a su rígido concepto de lengua, dejan al sujeto fuera de ésta. La corriente a la que nos referimos busca las regularidades sistemáticas existentes en la enunciación y analiza las categorias en que se manifiesta la intervención del sujeto, en otras palabras, las categorías gramaticales especializadas que marcan la relación del sujeto con su enunciado (personas, modalidades, temporalidad, deíxis, etc.). Esta línea de investigación toma como punto de partida la concepción de la enunciación según uno de sus principales teóricos, E. Benveniste':

"La enunciación supone la conversión individual de la lengua en discurso [...] En tanto que realización individual, la enunciación pude definirse, en relación con la lengua, como un proceso de apropiación. El locutor se apropia del aparato formal y enuncia su posición de locutor mediante indicios específicos." 84.

${ }^{1}$ E. Benveniste, Problemas de lingüistica general, II. México, Siglo xxı. Edit., 1977. p. 
Entre todos los indicios especificos que pueden relacionarnos al sujeto con su enunciado nosotros nos limitaremos al estudio de los deícticos en la lengua española. Advertimos ya de antemano que, dentro de este campo, no pretendemos hacer un estudio pormenorizado del fenómeno complejo de la deíxis en español sino una visión de los elementos más sobresalientes que nos ayuden a comprender la relación entre deixis y enunciación. Así pues, los indicios o conectores que trataremos serán los personales y las 10 calizaciones espacio-temporales que dependen de ellos.

\section{ENUNCIACIÓN Y DEÍXIS}

Ante todo debemos tener presente que los primeros elementos constitutivos de un proceso de enunciación son el locutor, el que enuncia; el alocutor, aquel a quien se dirige el enunciado. En otras palabras, el origen del discuro (yo de $1 .^{a}$ persona) y el interlocutor (el tú de $2 .^{a}$ persona).

Esta situación de primacía de los interlocutores en toda enunciación queda reconocida por algunos lingüistas. Así Bühler ${ }^{2}$ opina que podría considerarse a los personales como los primeros deicticos, en cuanto que señalan a dos elementos básicos de la comunicación, el emisor y el receptor. $T$. Todorov ${ }^{3}$ afirma que a partir de esta distinción de locutor y alocutorse puede concebir la organización de las formas lingüísticas indiciales de dos maneras, según se tomen como base categorías gramaticales o semánticas. Por su parte B. Pottier ${ }^{4}$ afirma que las operaciones enunciativas se pueden reagrupar en tres categorias: 1. ${ }^{a}$ interlocución (persona, interrogación, imperativo, etc.); 2. deíxis (dominio del espacio, del tiempo, etc.); 3 . $^{a}$ juicio. De igual manera E. Coseriu ${ }^{5}$ al hablar de la situación como operación de determinación en la técnica general del hablar, trata ciertos deícticos que "sitúan" los objetos denotados, es decir, que los vinculan con las "personas» implicadas en el discurso y se ordenan con respecto a las circunstancias espacio-temporales del discurso mismo. También E. Benveniste advierte «Está primero la emergencia de los indicios de persona (la relación yo-tú) que no se produce más que en la enunciación [...] De igual naturaleza y atinentes a la misma estructura de enunciación se encuentran los indicios de la ostensión (tipo este, aqui).

${ }^{1967}$ T. Todorov y O. Ducrot, Diccionario Enciclopédico de las Ciencias del lenguaje, Buenos Aires, Siglo XXI, edit. 1976.

B. Pottier, “Les modalités dans l'ensemble des opérations énonciatives». En La Psychomécanique et les théories de l'énonciation. Actes de la Table Ronde tenue a Lille les 16 et 17 Mars 1979. Presses Universitaires de Lille, 1980, pp. 67-78.

5 E. Coseriu, Teoria del lenguaje y lingüistica general, Madrid, Gredos, 1973, pp. 301 y ss.

6 Op. cit., p. 85 . 
De estas afirmaciones colegimos que, como resultado de la situación sobresaliente o preminente de las personas del discurso, las localizaciones espacio-temporales dependen de ellas.

Ahora bien, tanto las personas del discurso como el momento y la situación de enunciación dejan su huella en el enunciado y se manifiestan, principalmente, por las formas lingüísticas indiciales o deícticos de persona, de lugar y de tiempo. De ahí la importancia de los deícticos, resaltada por C. Kerbrat-Orecchioni cuando dice «les deictiques sont à considerer non seulement comme des unités de langue et de discours au même titre que toute autre unité linguistique, mais bien plus, comme ce qui rend posible l'activité discoursive elle-même ${ }^{7}$ ». Así pues, el estudio de la deíxis en el análisis de enunciados es de suma trascendencia puesto que es una de las operaciones constitutivas de éste. En efecto, todo enunciado se realiza en una situación definida por coordenadas espacio-temporales. El sujeto enunciador pone en relación su enunciado con los participantes en la comunicación o personas del discurso, con el momento de la enunciación y con el lugar en el que se produce el enunciado. Las referencias a esta situación forman la deíxis. En consecuencia, la deíxis supone una señalización, un proceso de individualización o actualización de lo designado en la situación y contextos concretos. En suma, como rasgos definitorios de la deíxis podemos presentar dos: 1) señalización; 2) actualización.

\section{LOS INDICIOS O DEÍCTICOS EN LAS TEORÍAS DE LA ENUNCIACIÓN. DEIXXIS Y LENGUA}

Ya desde la antigüedad la tradición gramatical ha reconocido la especificidad de ciertos términos que sólo adquieren valor a través de la actualización momentánea que les confiere la producción del enunciado en que aparecen. Así, por ejemplo, yo que puede remitir en lengua a cualquier persona que sea sujeto enunciador, en una enunciación particular designará a la persona determinada que dice yo. Estas unidades forman un sistema, el de los "indiciales» según Benveniste y tienen una gran importancia pues sirven de "puntos de anclaje» al mensaje, es decir, permiten determinar las «coordenadas cero" de la enunciación que son el yo-aqui-ahora del enunciador, a partir de las cuales se establecerán todos los valores derivados. Estos elementos son los «deícticos» según ciertos autores, denominados también «indicios» por Benveniste y «conectores» (shifters en inglés y embrayeurs en francés) por R. Jakobson ${ }^{8}$.

${ }^{7}$ C. Kerbrat-Orecchioni, L'énonciation de la subjectivité dans le langage, Paris, Armand Colin, 1980.

${ }^{8}$ El término embrayeur fue empleado por R. Jakobson que lo tradujo de shifter. En la traducción del libro de este autor Ensayos de lingüistica general, llevada a cabo por J. M. Pujol y J. Cabanes se traduce este término por conmutador. En el Diccionario de lingüística de J. Dubois et alli se denominan conectores. Por otra parte, A. Barrenechea en su articulo «El pronombre y su inclusión en el sistema de categorias semánticas" afirma que prefiere el término remitente. 
Fue R. Jakobson en su famoso texto de 1957 «Schifters, verbal categories and Russian verbs»" ${ }^{9}$ quien, tras el interés de lógicos como Frege o Russel y de lingüistas como Jespersen, puso el acento sobre los conectores en cuanto unidades del "código" que remiten al mensaje. Reciben esta denominación, según R. Jakobson ${ }^{10}$ aquellas unidades gramaticales cuya «significación no se puede definir sin hacer referencia o remitir al mensaje». Es decir, que estos morfemas no se pueden interpretar más que en relación al acto de enunciación único que ha producido el enunciado en el que se encuentran.

E. Benveniste, considerado como el teórico de la enunciación, cuando trata del aparato formal de la enunciación, expone su teoría sobre los que él denomina “indicios» y afirma al respecto ${ }^{11}$ : «Hay pues que distinguir las entidades que tienen en la lengua su estatuto pleno y permanente y aquellas que, emanadas de la enunciación, sólo existen en la red de "individuos" que la enunciación crea y en relación con el "qui-ahora" del locutor». Especifica más la naturaleza de estos elementos y dice: "las formas llamadas tradicionalmente "pronombres personales" "demostrativos" nos aparecen ahora como una clase de "individuos lingüisticos", de formas que remiten siempre y solamente a "individuos", trátese de personas, de momentos, de lugares, por oposición a los términos nominales que remiten siempre y solamente a conceptos. Ahora, el estatuto de estos "individuos lingüísticos" procede del hecho de que nacen de una enunciación, de que son producidos por este acontecimiento individual, [...] Son engendrados de nuevo cada vez que es proferida una enunciación, y cada vez designan de nuevo".

Tras las teorías sobre los conectores o indicios de sus principales definidores, podemos decir que en el enunciado existe una clase de elementos lingüisticos que tienen como papel «reflejar» su enunciación, integrar ciertos aspectos del contexto enunciativo. Entre estos elementos se encuentran los deícticos. Se ha discutido mucho sobre la naturaleza semántica de estos elementos. Hay lingü istas que los consideran como unidades vacías de contenido en si mismas y que sólo lo adquieren en una enunciación concreta, mientras que para otros, estos elementos poseen una significación lingüística general y estable pero la plenitud significativa la adquieren en cada enunciado $^{12}$. Así, por ejemplo, el adverbio aquí constituye una unidad del código de la lengua a la que se puede atribuir una significación general, pero para

${ }^{9}$ R. Jakobson, "Shifters, verbal catégories and Russian verb". Harward University, 1957. Recogido en Essais de linguistique générale, París, Minuit, 1963.

10 R. Jakobson, Ensayos de lingüistica general, Barcelona, Ariel, 1984, p. 310.

11 Op. cit., pp. 85 y 87 .

12 Consultar A. Barrenechea, "El pronombre y su inclusión en el sistema de categorias semánticas". (En Filologia. VIII, pp. 241-272). V. Lamiquiz en su obra Lingüistica española, Sevilla. Publicaciones de la Universidad de Sevilla, 1975, p. 357, considera a los deicticos semánticamente como «formas vacias de significación que se llenan de contenido semántico en relación con el tiempo lingüistico y la situación e interlocución del discurso". 
conocer su referente es preciso relacionarla con el acto de enunciación individual que lo soporta, puesto que en otro enunciado podrá remitir a otro lugar.

En conclusión, estos indicios son elementos lingüísticos enunciativos que constituyen categorías enteras dentro del sistema de la lengua y que remiten de una manera u otra a las instancias del discurso, es decir, a las personas, al momento del enunciado y a la situación en que se ha producido este enunciado. Precisamente, basándose en la evidencia de este hecho, ciertos tratamientos de la enunciación intentan integrarla en el sistema mismo de la lengua, como ya expusimos en el apartado 1.

\section{Clasificación de los indicios}

En concordancia con lo dicho en el apartado 2. de que la base de los fenómenos lingüísticos de la deíxis comporta señalización y actualización, debemos presentar una matización concerniente a los elementos de la enunciación que los deícticos señalan. La indicación puede ser sobre l) la situación espacial; 2) el momento temporal y 3) las personas del discurso.

En general, la deíxis personal se plasma en la categoría de los pronombres, mientras que la deíxis espacial y la temporal suelen plasmarse en la categoría de los adverbios.

Dada la primacía de las personas del discurso, como vimos anteriormente, en todas las clasificaciones realizadas por los lingüistas destacan, en primer lugar, los indicios personales frente a los de ostensión (Benveniste) o localizaciones espacio-temporales (Jakobson) o elementos de la «situación" (Coseriu). Por tanto, si la deíxis comporta un sistema personal, un sistema espacial y un sistema temporal, empezamos la exposición por los indicios personales.

Nos limitaremos a la deixis mostrativa, es decir, la que comporta una señalización hacia la realidad extralingüística y no hacia el contexto lingüístico que sería la deíxis anafórica, aunque como dice Bühler $r^{13}$ "se debe utilizar deixis en el concepto amplio pues hay también una mostración de lugares en la estructura del discurso".

\subsection{Indicios personales en el sistema de la lengua española.}

No vamos a ralizar una exposición exhaustiva de los indicios personales, pues se puede encontrar en otros estudios. No obstante, nos parece oportuno hacer algunas precisiones con vistas a presentar los elementos indiciales de persona que existen en la lengua española.

${ }^{13}$ Op. cit, p. 195. 


\subsubsection{La categoría de «persona» y el discurso}

Generalmente se ha presentado la categoría de persona organizada en tres personas gramaticales $\left(1 .{ }^{\mathrm{a}}, 2{ }^{\mathrm{a}}\right.$ y $\left.3{ }^{\mathrm{a}}\right)$. En esta línea se encuentra la Real Academia pues en el Esbozo $o^{14}$ dice "Las personas del discurso son tres: yo (1. persona) señala al mismo que pronuncia o escribe esta palabra, $t \dot{u}$ ( 2 . $^{a}$ persona) a la persona o cosa a la que interpela la primera persona, él (3. ${ }^{a}$ persona) a la persona o cosa que no es yo ni $t \dot{u})$. De acuerdo con este planteamiento muchos autores como V. Lamíquiz ${ }^{15}$ aceptan estas tres personas. Este autor ha estudiado la relación que establece la lengua entre el sistema deíctico y las personas gramaticales, creándose un sistema ternario, que se da tanto en los pronombres personales $(y o, t u ́, e ́ l)$ como en los demostrativos (este, ese, aquel) y en las formas adverbiales (aqui, ahi, alli) existiendo en cada sistema un evidente paralelismo.

La perspectiva o teoria de la enunciación defiende postulados que difieren de lo anteriormente expuesto. A este respecto debemos exponer las ideas que sobre la "persona» y el discurso (instancias del discurso) presenta E. Benveniste ${ }^{16}$. Propone la necesidad de separar las dos primeras personas de la tercera, a la cual niega la categoria de persona, tanto en la forma verbal como en el pronombre personal. Dice así: "la "3. " persona" no es una "persona"; es incluso la forma verbal que tiene por función expresar la no-persona». En lo que respecta al pronombre personal afirma «Esta (la noción de "persona") es propia tan sólo de yo/tú y falta en él». La razón estriba en que yo/tú, son pseudo-signos lingüísticos que sólo remiten a la instancia del discurso en que son emitidos. Es decir, que para yo/tú se necesita el contexto situacional mientras que para él es el contexto lingüístico. Por tanto, las dos primeras personas, como afirma $\mathrm{E}$. Benveniste, son caracteristicas «de lo que llamaremos las "instancias del discurso", es decir, los actos discretos y cada vez únicos merced a los que la lengua se actualiza en palabra en un locutory.

Junto a estas afirmaciones tenemos la precisión de M. ${ }^{4} \mathrm{C}$. Bobes Naves $^{17}$, que, tras ponerse en la perspectiva del estudio de la lengua con relación al proceso, define tres niveles en el proceso del habla: 1) nivel del sujeto que usa la lengua (SP); 2) nivel de lengua y 3 ) nivel del sujeto a quien va dirigido, u oyente (SS). Examina bajo este enfoque la diferenciación de E. Benveniste entre yo/tú por un lado y él (no-persona) por otro y explica: "Creemos que se trata más bien de planos diferentes: YO/TÚ intervienen

\footnotetext{
14 Esbozo de una nueva gramática de la lengua española, Madrid, Espasa Calpe, 1978.

is V. Lamiquiz, "El demostrativo en español y en francés. Estudio comparativo y estructuración» (Es Revista de Filologia Española, t. L, pp. 163-202).

16 E. Benveniste, Problemas de lingüistica general, I. México, Siglo xxı editores, 1974, pp. 164 y ss.

17 M." C. Bobes Naves, Las personas gramaticales, Universidad de Santiago de Compostela. Secretariado de Publicaciones de la Universidad. 1971.
} 
en forma directa en el proceso lingüistico como SP y SS, mientras que ÉL no excede los límites de la lengua: es indiferente que se refiera a persona o cosa, o que se elimine (impersonales)". Coincide en líneas generales con E. Benveniste pues observa una correlación entre la $1 .^{\mathrm{a}}$ y la 2 . $^{\mathrm{a}}$ pero no entre estas dos y la $3 .^{a}$ persona.

Asimismo para J. Schmidely ${ }^{18}$ en la categoría de persona nos encontramos, por un lado, la no-persona y, por otro, la persona propiamente dicha, la cual subdivide en referencia al locutor y referencia al alocutor o destinatario, $y$ añade Schmidely «División ternaire que se ramène à l'opposition de deux binarités comme le propose fort justement Benveniste (1946): corrélation de personalité opposant la personne à la non-personne, et corrélation de subjectivité opposant la personne que parle et celle à qui elle parle».

Una vez precisado el concepto de "persona" en la teoría de la enunciación podemos iniciar el examen de las formas lingüísticas pertenecientes a la lengua española que la manifiestan en el discurso. Estas formas son: pronombre y adjetivo personal así como la forma verbal.

\subsubsection{Pronombres personales}

En lo que respecta a los pronombres en general, no todos los lingüistas están de acuerdo en la naturaleza de estos indicios o conectores. Algunos autores les niegan la existencia de contenido nocional, otros, afirman la aptitud del pronombre para recibir un contenido ocasional. Así la Real Academia en el Esbozo... dice: «Son nulos o escasos los contenidos semánticos del pronombre». Por otra parte, R. Seco afirma «El pronombre designa a los seres sin caracterizarlos; los señala, actuando en la frase, en el diálogo, igual que un dedo índice: yo, ahi, aquel, tuyo [...] Nótese la ausencia de un significado fijo en estas palabras. Su significación depende siempre de la situación ${ }^{19}$.

Nosotros adoptamos la definición de J. Schmidely ${ }^{20}$ «Le pronom est un gramème à signification générique, référant à toute entité compatible avec ce contenu et ne prenant une valeur spécifique que dans la communication". En consecuencia, podemos decir que los pronombres son unos operadores de la conversión de la lengua en discurso, puesto que sólo en éste tienen significación plena. Si hacen referencia directamente al sistema de las personas tendremos lo que denominamos pronombres personales.

En el campo de los pronombres personales existentes en la lengua espa-

$18 \mathrm{~J}$. Schmidely, La personne grammaticale et son expression en langue espagnole. Thèse presentée devant l'Université de Paris IV. Atelier reproduction des thèses. Université de Li. lle $1_{19} \mathrm{~g}, 1979$. p. 18.

19 R. Seco, Manual de gramática española, Madrid, Aguilar, 1971, p. 38.

20 Op. cit., p. 210. 
ñola se verifica una delimitación al tener en cuenta la perspectiva de la enunciación. En efecto, desde este enfoque y como indicios directos de persona sólo tienen interés los pronombres personales de $1 .^{a}$ y $2 .^{a}$ persona, puesto que son los que designan los dos protagonistas de la enunciación:

- para el locutor $\left(\mathrm{P}_{1}\right)$ yo, me, mi.

- para el alocutor $\left(\mathrm{P}_{2}\right)$ tú, te, ti.

Según Schmidely que recoge las teorías de Benveniste, el plural sólo podría atribuirse a las asociaciones homogéneas.

- nosotros $=$ asociación homogénea $\left(\mathrm{P}_{1}+\mathrm{P}_{1}\right)=$ plural.

- nosotros $=$ asociación heterogénea $\left(\mathrm{P}_{1}+\mathrm{P}_{2}\right)$.

- vosotros $=$ asociación homogénea $\left(\mathrm{P}_{2}+\mathrm{P}_{2}\right)=$ plural.

Es de resaltar el hecho de que además de por los pronombres correspondientes a su rango personal, el locutor y el destinatario pueden estar manifestados o señalados por los sustitutos.

yo puede presentarse por:

- nosotros de tipo inclusivo.

- tú o vosotros.

- 3. persona en forma pronominal (indefinido: uno,etc.).

- formas nominales: nombre propio, profesión, etc.

- perifrasis: "El que ahora os dirige la palabra».

tú - sustitutos:

- la no-persona: uno, él, ella, ello, etc.

- expresiones de tratamiento: usted, Vuestra Alteza, etc.

\subsubsection{Adjetivos personales}

Son categorías deícticas con función de referencia nominal. Podemos clasificarlos, siguiendo a P. Carbonero ${ }^{21}$ en adnominales (si funcionan como actualizadores en el sintagma nominal) o pronominales (si funcionan sustituyéndolo). En general, actualizan, sitúan la designación.

La polémica sobre la denominación de estas formas lingüísticas como pronombres posesivos o no pronombres está entablada hace ya tiempo. Nos acogemos a la decisión de J. Schmidely de denominarlos «adjetivos personales».

21 P. Carbonero Cano, Deixis espacial y temporal en el sistema lingüistico, Sevilla, Secretariado de publicaciones de la Universidad, 1979, p. 25. 
Existe una afinidad entre los adjetivos y los pronombres personales que resalta J. Schmidely de la siguiente manera: «Las dos series responden a la misma necesidad del lenguaje - la referencia de una entidad al sistema de la persona - y a los mismos criterios de organización - el rango personal y la integración en el enunciado».

El valor de base de los adjetivos personales es su estrecha relación con la noción de persona.

Es significativa la gran correspondencia que ofrecen los significantes de los adjetivos personales con los de los pronombres personales. Son adjetivos personales:
mi, mio.
tu, tuyo.
su, suyo.
nuestro.
vuestro.

\subsubsection{Forma verbal}

Como ya hemos visto, una forma de manifestarse la persona gramatical en español es por los pronombres pero, con mucha frecuencia, éstos están latentes pues las desinencias verbales en castellano son índice suficiente de las personas gramaticales. Por tanto, en español, no es necesario la expresión del sujeto por medio del pronombre cuya utilización obedecerá a fines estilisticos (redundancia, énfasis, etc.).

Queda claro que toda forma verbal, con excepción de las formas no personales (infinitivo, gerundio, participio), comporta una marca que indica un rango personal determinado. Es decir, que el verbo, valiéndose de las desinencias de persona realiza señalamientos de la misma naturaleza que los del pronombre personal.

En correlación con lo expuesto sobre los pronombres personales, en la perspectiva de la enunciación son importantes las formas verbales de 1. $y$ 2. ${ }^{a}$ persona, puesto que, como afirma J. Schmidely «En la 1. a y 2." personas, la forma verbal declara al mismo tiempo el rango personal de la entidad en cuestión y también la identifica por las condiciones de la comunicación”22.

Para P. Carbonero «las formas personales de los verbos tienen en sí referencias deíticas temporales y también hacia las personas lingüísticas. Pero tal valor deictico no está tanto en el lexema verbal, como en los gramemas que lo modifican $)^{23}$. Por lo que concluye que más que valor deictico-situacional puede caracterizarse como valor designativo.

\footnotetext{
22 Op. cit., p. 149.

23 Op. cit., p. 25.
} 


\subsection{Indicios de ostensión en el sistema espacial de la lengua española}

Según E. Benveniste los indicios de ostensión son «términos que implican un gesto que designa el objeto al mismo tiempo que es pronunciada la instancia del término» ${ }^{24}$. Corresponden a las localizaciones espacio-temporales de $\mathbf{R}$ Jakobson. Dependen todos ellos de los indicios de persona. Por tanto, junto a las personas existen otros conectores, otros deícticos, cuya función es inscribir los enunciados-ocurrencias en el espacio y en el tiempo con relación al enunciador, es decir, que indican sobre la situación espacial y el momento temporal. Esto implica que no se pueden disociar personas y deícticos, pues el yo-aqui-ahora es indisociable.

Trataremos por separado la deíxis de situación y la temporal, aunque es una distinción metodológica ya que los sistemas espacial y temporal se intercambian las unidades.

En lo que respecta al sistema espacial diremos que el punto de referencia de los deicticos espaciales es la posición que ocupa el cuerpo del enunciador en el momento de su acto de enunciación.

A pesar de que, como ya vimos, la deixis espacial, en español, suele plasmarse morfosintácticamente en la categoria de adverbios, sin embargo, debemos reconocer que ésta también se puede registrar en otras categorías. $P$. Carbonero ${ }^{25}$ distingue tres modos de manifestación de la deíxis espacial: a) Las formas que gramaticalmente son consideradas de funcionamiento nominal; b) Las formas que gramaticalmente pueden considerarse de funcionamiento verbal y c) las unidades adverbiales.

\subsubsection{Formas consideradas de funcionamiento nominal}

Son categorías deícticas con función de referencia nominal (adnominal o pronominal). En general, actualizan, sitúan la designación que comporta el sustantivo. A este conjunto corresponden los demostrativos como este, ese, aquel. P. Carbonero considera que estas formas «no son portadoras del rasgo "espacial" exclusivamente, sino que pueden penetrar en el terreno del espacio (este sitio), el tiempo (aquel año) o cualquier otra noción (ese problema). Su capacidad de referencia es muy amplia en este aspecto y el contenido de lugar o de tiempo expresado por ellos no está en sí mismos, sino en el sustantivo al que acompañan o al que sustituyen». Y concluye «No hay, pues, en el funcionamiento nominal, unidades diferenciadas de referencia espacial».

\footnotetext{
24 Op. cit., II. p. 88.

25 Op. cit., pp. 65 y ss.
} 
No obstante, esbozamos un estudio de estas formas deícticas en la lengua española. Recordamos que hay autores que, basándose en las tres personas gramaticales, defienden un sistema ternario de oposiciones al estudiar la relación que establece la lengua entre el sistema deictico y las personas gramaticales. En el caso de las formas de funcionamiento nominal sería este, ese, aquel.

Nosotros, al tratar los demostrativos preferimos mantener la terminología de indiciales de campo, dado que lo enfocamos desde la perspectiva de la enunciación. Así pues, nos basamos en lo que manifiestan J. Alcina y J. M. Blecua ${ }^{26}$ respecto a los demostrativos y los campos. Para explicar estos últimos afirman que, en el discurso, el hablante "se atiene a una organización de la realidad para la que toma como puntos de referencia las dos personas que intervienen en el diálogo: el que habla (emisor) y el que escucha (receptor). Según esta organización cada uno de los que intervienen en el diálogo ocupa un campo de referencia. Un tercer campo está constituido por lo que queda fuera de los dos campos que ocupan los interlocutores". Estos tres campos de referencia serán: a) el que habla y su campo; b) el que escucha y su campo; c) el que ni habla ni escucha y su campo, trazado por oposición y exclusión de los anteriores.

Los demostrativos funcionan como sustantivos o como adjetivos antepuestos o postpuestos al sustantivo que determinan. En este sentido D. Maingueneau ${ }^{27}$ establece la diferenciación entre los deícticos puros y los que se combinan con un nombre, los cuales, por su significado, restringen ya considerablemente la clase de los posibles referentes del grupo nominal.

Según J. Alcina y J. M. Blecua ${ }^{28}$ los demostrativos sitúan, como sustantivos, el sustantivo al que aluden o, como adjetivos, al sustantivo que acompañan en relación con los tres campos referenciales anteriormente mencionados. Así pues, teniendo en cuenta estos campos podemos clasificar los demostrativos de la siguiente manera:

\begin{tabular}{|c|c|c|c|c|c|}
\hline Campo 1 & $\begin{array}{l}\text { masc. sing. } \\
\text { est- } \begin{array}{l}\text { es- } \\
\text { es }\end{array}\end{array}$ & fem. sing. & masc. pl. & fem. pl. & neutro \\
\hline Campo 3 & aquel- $\varnothing$ & $-\mathbf{a}$ & $-0 s$ & -as & -0 \\
\hline
\end{tabular}

\subsubsection{Formas consideradas de funcionamiento verbal}

Existen algunas unidades deícticas que sitúan el proceso verbal designado en una localización espacial o temporal. Nos referimos a ciertos «adverbios» y "preposiciones» de la gramática tradicional que están capacitados

26 J. Alcina y J. M. Blecua, Gramática española, Barcelona, Ariel, 1983, p. 592.

27 D. Maingueneau, Approche de l'énonciation en linguistique française, Paris, Classiques Hachette, 1981, p. 22.

28 Op. cit., p. 621 . 
para una referencia espacial y temporal. Un ejemplo lo tenemos en las formas a y por en "Sube a casa" - "Sube a las cinco"; "Ha salido por la puerta" - «Ha salido por una semana".

Ahora bien, P. Carbonero afirma que «en las preposiciones [...] tampoco existen claramente paradigmas diferenciados para el espacio y para el tiempo ${ }^{29}$.

\subsubsection{Elementos adverbiales}

En el nivel morfosintáctico es en la categoría de los adverbios donde, generalmente, se plasma la deíxis espacial o temporal.

Frente a las dos formas gramaticales anteriormente estudiadas, las unidades adverbiales se diferencian en el hecho de que los rasgos "espacio" y "tiempo" suelen estar contenidos en sí mismos, y por ello pueden encontrarse paradigmas diferenciados para cada tipo de referencia ya sea temporal o adverbial. Puesto que se organizan sistemáticamente en la lengua con este rasgo específico podemos afirmar que en la lengua española existe un sistema espacial en los deícticos. Son varias las clasificaciones que se han realizado de estos adverbios. Así, en lo que respecta a la lengua española tenemos: subjetivos o deícticos (aqui...), y objetivos (arriba...) según F. Marcos Marin ${ }^{3()}$; pronominales locativos (aqui, hoy, etc.) según J. Alcina y J. M. Blecua ${ }^{31}$; deicticos para V. Lamiquiz ${ }^{32}$, etc. Seguimos las orientaciones de P. Carbonero tanto en los adverbios espaciales como en los temporales por parecernos más acordes con el enfoque de este trabajo. Según este au$\operatorname{tor}^{33}$ en el sistema espacial podemos agrupar los deícticos en pares o tríos de oposición, de acuerdo con su valor funcional y las relaciones que presenten entre sí:

1) aqui / ahi / alli.

2) acá / allá.

3) encima / debajo.

4) arriba / abajo.

5) delante / detrás / enfrente.

6) adelante / atrás.

7) cerca / lejos.

8) dentro / fuera / alrededor.

9) adentro / afuera.

10) donde / adonde.

29 Op. cit., p. 65

30 F. Marcos Marín, Curso de gramática española, Madrid, edit. Cincel, 1984. p. 308.

31 Op. cit. p. 704.

32 Op. cit., p. 356

33 Op. cit., p. 66. 
En conjunto podemos decir que existen cuatro subsistemas de unidades funcionando en el sistema espacial:

1) subsistema personal: aqui, acá, ahi, alli, allá.

2) subsistema de los descriptivos dimensionales: encima, debajo, arriba, abajo, delante, detrás, enfrente, adelante, atrás.

3) subsistema de los descriptivos no dimensionales: cerca, lejos, dentro, fuera, alrededor, adentro, afuera.

4) subsistema de espaciales fóricos: donde, adonde.

La principal diferencia de los tres primeros subsistemas con respecto al cuarto es que en este último las unidades muestran con respecto a una situación determinada por el contexto, mientras que los primeros lo hacen con respecto a la situación espacial que rodea a los interlocutores. Esta diferencia es esencial para nuestro enfoque enunciativo.

También es importante, desde nuestro punto de vista de la enunciación, especificar la diferencia entre personales y descriptivos. Los adverbios calificados de «personales» presentan una referencia a las personas de las interlocución. Por tanto, según la persona lingüística con que se relacione el lugar indicado, se seleccionará una forma diferente que nos brinda el sistema. Por el contrario, en los descriptivos no existe una especialización de las unidades de acuerdo con que el punto de referencia esté en el ámbito del yo, tú o él.

4.3. Indicios de ostensión en el sistema temporal de la lengua española.

El punto de referencia de las indicaciones de tiempo de los deícticos temporales es el momento en que el enunciador habla, el «momento de la enunciación» que define el presente lingüístico. El locutor ordena la cronología de su enunciado con relación a su propio acto de enunciación y la impone a su alocutor. Por consiguiente, trataremos las unidades que sirven para "situar" la predicación o el proceso verbal en la coordenada que está relacionada con la propia situación temporal en que se produce la intercomunicación.

Nos limitaremos a destacar las unidades léxicas. No obstante, debemos recordar que existen otros recursos para expresar la deíxis temporal como, por ejemplo, las unidades complejas lexicalizadas: antes de ayer, pasado mañana, hace poco, etc. También, según afirma R. Jakobson, los tiempos verbales desempeñan el papel de conectores por su facultad de señalar un suceso anterior o posterior a la enunciación del mensaje.

Siguiendo las orientaciones de P. Carbonero, en el sistema temporal español existen tres subsistemas básicos de funcionamiento:

a) Mostrativos internos: adverbios que puedan quedar encuadrados en un funcionamiento de época, refiriéndose unos al pasado, otros 
al presente y otros al futuro. Son: ayer, anoche, antes, anteriormente, ahora, hoy, entonces, todavia, aún, ya, mañana, posteriormente, luego, después.

b) Mostrativos externos o descriptivos:

No penetran en unos valores de diferenciación de época. En su valor semántico-funcional suelen "describir» de alguna otra manera la situación temporal a la que se refieren. Son: siempre, a veces, nunca, jamás, mientras, pronto, temprano, tarde.

c) Fórico: cuando.

Recordemos que, desde el punto de vista de la enunciación, sólo se tienen en cuenta los mostrativos y particularmente, los internos.

\section{CONClusiones}

Esta somera exposición de la deíxis y, por tanto, de únicamente parte de los fenómenos enunciativos, puede darnos una idea de la gran cantidad de elementos indiciales existentes en la lengua española. El reconocimiento de la presencia de estos elementos enunciativos en lengua puede servir para explicar el empeño de ciertos lingüistas, divergentes en sus teorías como Pottier, Guillaume, Culioli, etc., para integrar al sujeto en el sistema mismo de la lengua. Esta postura implica una reformulación del concepto de «langue" de Saussure así como un rechazo de la "parole» saussureana. Los "productos" de la actividad lingüística reciben el nombre de discurso según Pottier y Guillaume, mientras que Culioli los denomina texto.

Los argumentos que justifican esta integración del sujeto son, según C. Fuchs $^{34}$, de dos tipos. Por una parte, la imposibilidad de divorciar la función designativa de las otras funciones en la actividad lingüística. Recordamos que la "función emotiva» refleja la actitud del locutor con relación a su discurso. El otro argumento que se esgrime es la existencia, en el sistema de la lengua, de categorias que remiten de manera más o menos directa a los dos sujetos, al momento de la enunciación y a la situación de enunciación.

Este trabajo sobre la deíxis en la lengua española puede ser una aportación para poner de manifiesto el fundamento o razón del último argumento expuesto.

34 C. Fuchs, "Quelques réflexions sur le statut linguistique des sujets énonciateurs et de l'énonciation". En La psychomécanique et les théories de l'énonciation, Actes de la Table Ronde tenue á Lille les 16 et 17 Maars 1979. Presses Universitaires de Lille, 1980. 